\title{
Engaging the missing link: Evidence from FALAH for involving men in family planning in Pakistan-Case study
}

Seemin Ashfaq

Population Council

Maqsood Sadiq

Follow this and additional works at: https://knowledgecommons.popcouncil.org/departments_sbsr-rh

Part of the Demography, Population, and Ecology Commons, Family, Life Course, and Society Commons, and the International Public Health Commons How does access to this work benefit you? Let us know!

\section{Recommended Citation}

Ashfaq, Seemin and Maqsood Sadiq. 2015. "Engaging the missing link: Evidence from FALAH for involving men in family planning in Pakistan-Case study." Washington, DC: Population Council, The Evidence Project. 


\section{Engaging the Missing Link: Evidence from FALAH for Involving Men in Family Planning in Pakistan \\ II \\ 0 \\ $\leftarrow$ \\ Seemin Ashfaq \\ 0 \\ Maqsood Sadiq}

June 2015

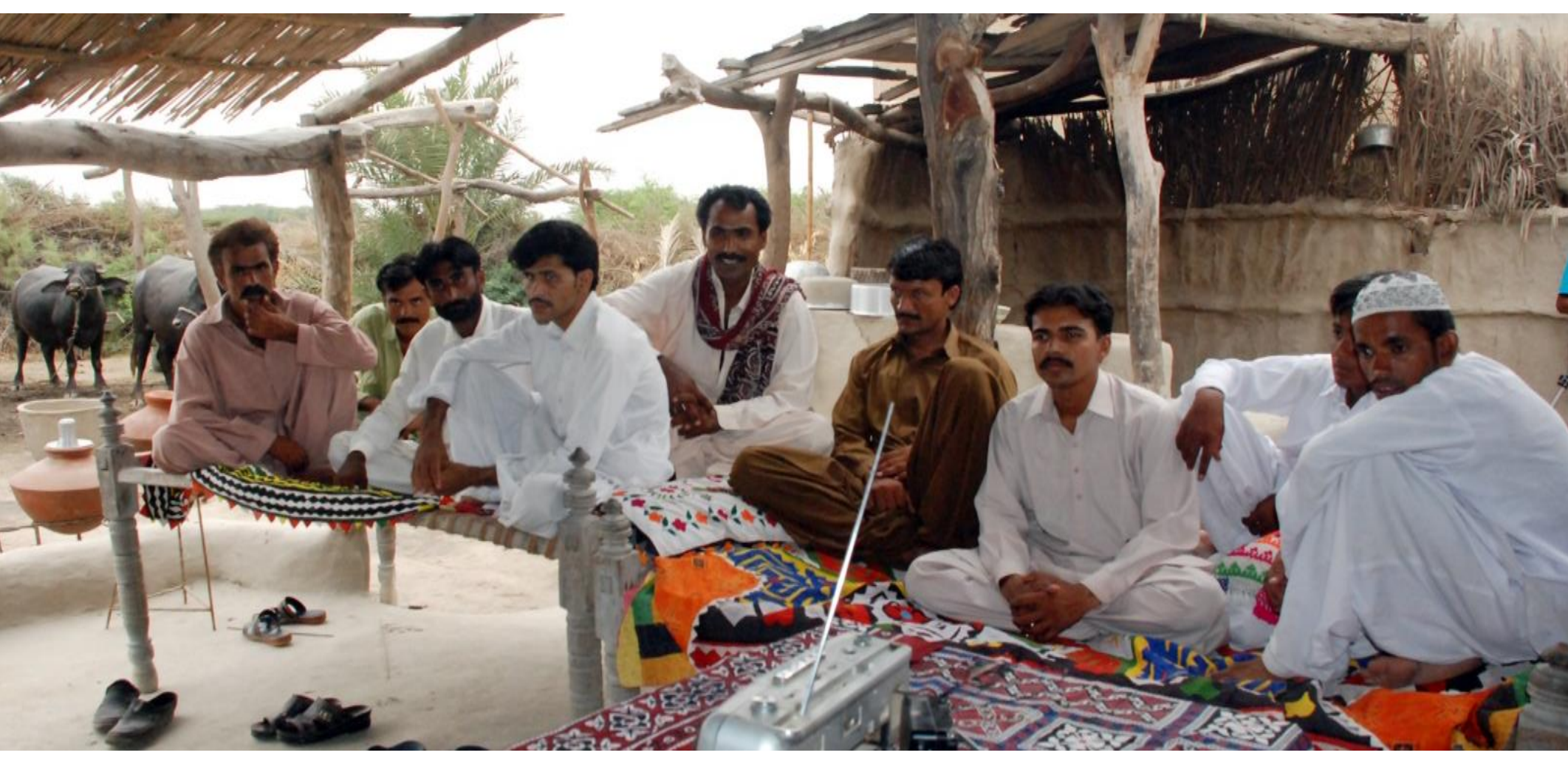





\section{Engaging the Missing Link: Evidence from FALAH for Involving Men in Family Planning in Pakistan}

Seemin Ashfaq, Deputy Director Programs, Population Council, Pakistan Maqsood Sadiq, Senior Program Officer, Population Council, Pakistan

June 2015 


\section{The Evidence Project}

Population Council

4301 Connecticut Avenue, NW, Suite 280

Washington, DC 20008 USA

tel +12022379400

evidenceproject.popcouncil.org

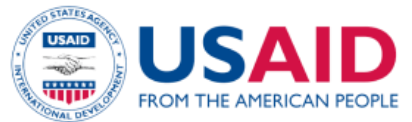

The Evidence Project is made possible by the generous support of the American people through the United States Agency for International Development (USAID) under the terms of cooperative agreement no. AID-

OAA-A-13-00087. The contents of this document are the sole responsibility of the Evidence Project and Population Council and do not necessarily reflect the views of USAID or the United States Government.

The Evidence Project uses implementation science-the strategic generation, Evidence translation, and use of evidence-to strengthen and scale up family planning and reproductive health programs to reduce unintended pregnancies worldwide. The Evidence Project is led by the Population Council in partnership with INDEPTH Network, International Planned Parenthood Federation, Management Sciences for Health, PATH, Population Reference Bureau, and a University Research Network.

Published in June 2015.

Suggested citation: Ashfaq, Seemin and Maqsood Sadiq. 2015. "Engaging the Missing Link: Evidence from FALAH for Involving Men in Family Planning in Pakistan," Case Study. Washington, DC: Population Council, The Evidence Project.

Photo credit on cover page: Mansoor Qaisar, Population Council Pakistan.

(C) 2015 The Population Council, Inc. 


\section{Table of Contents}

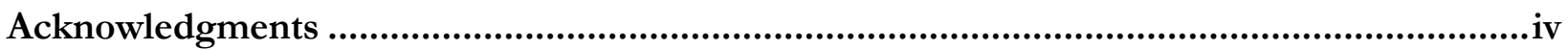

List of Acronyms..................................................................................................................

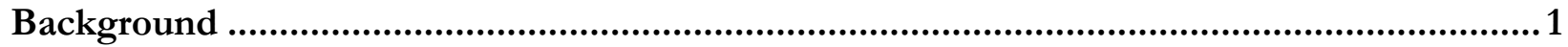

Engaging Men in Pakistan: The FALAH Strategy .............................................................3

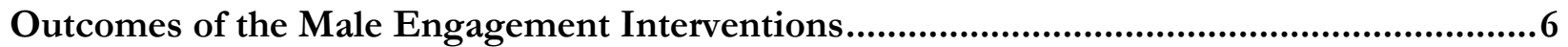

1. Man Talk: Male Community-based Volunteers ..............................................................................6

2. Peers for Planning: Men’s Group Meetings ………..................................................................... 9

3. Clear Conscience: Sermons by Sensitized Mosque Leaders........................................................11

4. Collective Reflection: Interactive Community Theater ...............................................................14

5. Mass Communication: The Electronic Media Campaign ...............................................................15

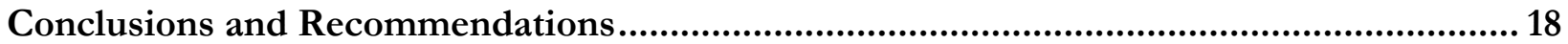

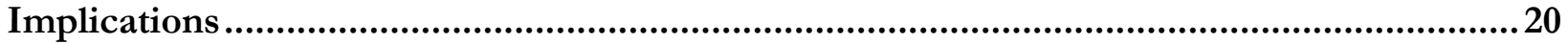

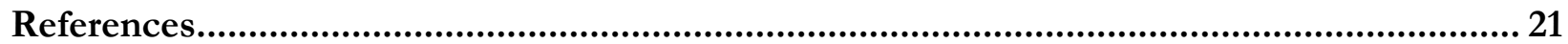




\section{Acknowledgments}

We would like to express our profound gratitude to Dr. Zeba Sathar, Country Director Population Council Pakistan, for guiding us in the preparation of this document. We benefitted at each step from her invaluable support and intellectual contributions.

We appreciate the thoughtful review and comments from USAID colleagues: from USAID/Pakistan, Monica Villanueva, Health Office; from USAID's Bureau of Global Health/Office of Population and Reproductive Health/Research/Technology and Utilization Division, Mihira Karra, Chief, Shawn Malarcher, Research Utilization Advisor, Erika Martin, Senior Implementation Science Advisor, and L. Caitlin Thistle, Program Analyst; and from the Policy, Evaluation and Communications Division, Michal Avni, Gender Advisor. We also acknowledge Joan Kraft, Gender Advisor, Centers for Disease Control and Prevention.

We are grateful to Dr. Karen Hardee, Senior Associate and Director of the Evidence Project, and to Ms. Ellen Weiss, Senior Communications Specialist of the Evidence Project, for technically reviewing the paper and providing very useful contributions.

We extend our special thanks to Ms. Kiren Khan for editing the document and to Ms. Anneka Van Scoyoc for formatting and design.

We would like to thank the provincial policymakers for sharing their insights and helpful recommendations. 


\section{List of Acronyms}

$\begin{array}{ll}\text { BCC } & \text { Behavior Change Communication } \\ \text { CBV } & \text { Community-Based Volunteers } \\ \text { CMO } & \text { Community Mobilization Officers } \\ \text { CPR } & \text { Contraceptive Prevalence Rate } \\ \text { FALAH } & \text { Family Advancement for Life and Health Project } \\ \text { HANDS } & \text { Health and Nutrition Development Society } \\ \text { HTSP } & \text { Healthy Timing and Spacing of Pregnancies } \\ \text { IEC } & \text { Information, Education, and Communication } \\ \text { KP } & \text { Khyber Pakhtunkhwa Province } \\ \text { LHW } & \text { Lady Health Worker } \\ \text { MGM } & \text { Men's Group Meetings } \\ \text { NGO } & \text { Non-Governmental Organization } \\ \text { PDHS } & \text { Pakistan Demographic and Health Survey } \\ \text { RSPN } & \text { Rural Support Programme Network } \\ \text { VHC } & \text { Village Health Committee } \\ \text { WHO } & \text { World Health Organization }\end{array}$




\title{
Background
}

\author{
IN A PROVINCE LIKE KP [KHYBER PAKHTUNKHWA] WHERE MEN MAKE DECISIONS ON ALL \\ FAMILY MATTERS, INCLUDING THE NUMBER OF CHILDREN THE COUPLE SHOULD HAVE, IT \\ BECOMES REALLY IMPORTANT TO INVOLVE THEM [IN FAMILY PLANNING INTERVENTIONS].
}

Secretary, Population Welfare Department, Khyber Pakhtunkhwa, October 2014

\begin{abstract}
Although family planning programming has been ongoing in Pakistan for nearly 50 years, 20 percent of women have unmet need, fertility remains high at 3.8 children per woman, and only 35 percent of married couples today are using a contraceptive method. ${ }^{1}$ Compared with other countries in the region, Pakistan's fertility transition has been extremely slow, and the goal of achieving a 55 percent contraceptive prevalence by 2020, committed at the 2012 London Summit, remains far from reach. With demographic pressures exacerbating the already critical development issues facing the country, there is an urgent need to redouble family planning efforts and to address the gaps presently compromising its effectiveness.

One such gap is the exclusion of men from family planning programming. While Pakistan's health and population systems have multiple options for women to discuss family planning and obtain services, far fewer opportunities exist for men. Family planning is widely perceived as a woman's concern: programs most often target women, and "family planning communication" evokes the image of a campaign to encourage women to use contraception.
\end{abstract}

\section{Husbands' Approval is a Decisive Factor in Contraceptive Uptake}

Men's actual and perceived views, and their decision-making powers play an important role in the seeking of reproductive health care by families, including delivery, antenatal care, immunizations, and especially family planning. ${ }^{2,3}$ In Pakistan, studies repeatedly identify the husband's approval as one of the most influential contributors to acceptance of a family planning method in both rural and urban areas., ${ }^{4,5} \mathrm{~A}$ study in Punjab found that while couples' desires play a significant role in the uptake of contraceptives, women's perceptions of their husband's approval comprise the strongest predictor of current use of contraceptives. ${ }^{6}$

"There is a general hold of men in our society. Women cannot do things such as use of family planning without the permission of men (their husbands). Since men play an important role, everything will be fine if men are convinced." 5

-Female, in-depth interview, rural Okara

"No matter how much a woman is motivated, there is no way she would willingly adopt family planning methods unless her husband agrees to it. A method can only be adopted when both concerned parties talk to each other about it." 5

-Male, focus group discussion, urban community Bahawalpur

This sentiment is echoed in many other developing societies where it has been shown that the husband's desires have an important effect on a couple's fertility. 5,7

\section{Men's Growing Support for Family Planning}

Data from the Pakistan Demographic and Health Survey (PDHS) 2012-13 and other research studies show that men are supportive of involvement in family planning in Pakistan. The PDHS 2012-13 found that 76 percent of men ( 86 percent urban and 72 percent rural) disagreed with the idea that contraception is a woman's business and a man should not have to worry about it. 
Over the last two decades, there have been significant changes in men's fertility preferences and contraceptive use. Compared with 1990-91, men are much more likely to want fewer children (Figure 1). The proportion of male contraceptive methods (condom, male sterilization, and withdrawal) in overall methods used has increased over the same period, from 33 percent of the total contraceptive prevalence rate (CPR) in PDHS 1990-91 to 50 percent in PDHS 2012-13 (Figure 2).

\section{FIGURE 1}

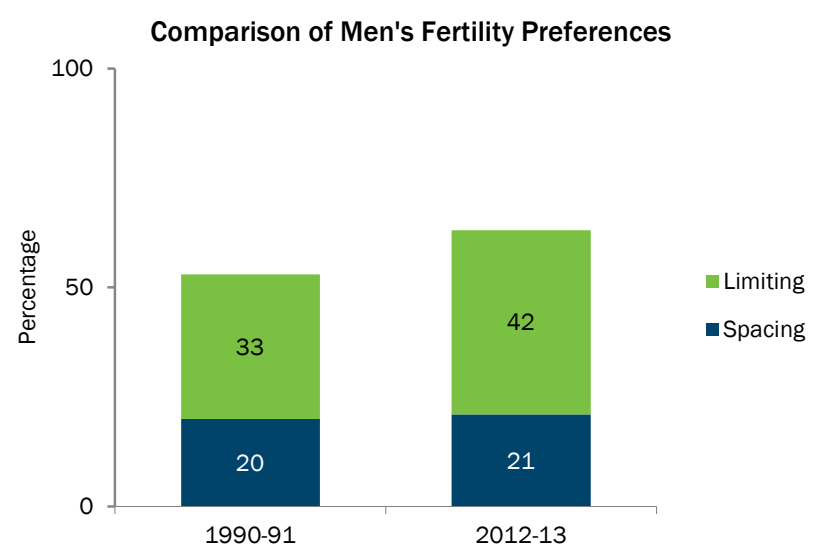

\section{FIGURE 2}

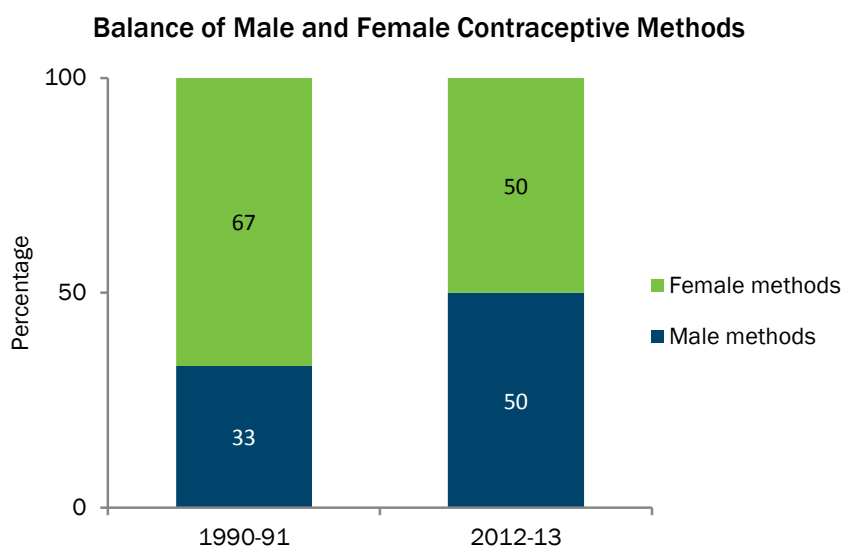

In fact, men express a clear desire to be involved in family planning interventions. In a qualitative study, male respondents expressed their frustration at having no source of information available to them at the community level and listed several reasons for not using contraceptive methods, including the nonavailability of contraceptives, experienced and perceived side effects of contraceptives, contraceptive failure, and contraceptive costs. ${ }^{5}$ This needs to change.

"A program initiated through men will be more effective ... 70 percent of the population lives in rural areas in Pakistan. Success in rural areas can only be achieved if men in those areas are properly motivated." 5

-Male, focus group discussion, South Punjab 


\section{Engaging Men in Pakistan: The FALAH Strategy}

Results from the USAID-funded Family Advancement for Life and Health project (FALAH), implemented in 2008-12, show that the inclusion of men in family planning efforts is a feasible and effective intervention to help shift attitudes and behaviors in Pakistan and perhaps in other countries in the region and globally as well. ${ }^{8}$

Implemented by a consortium of nongovernmental organizations (NGOs) led by the Population Council, with partners Greenstar-Social Marketing, Health and Nutrition Development Society (HANDS), JHPIEGO, Rural Support Programme Network (RSPN), and Save the Children (USA), FALAH aimed to reduce unmet need and improve access to family planning services through community-based interventions in 20 districts in Pakistan's four major provinces; Punjab, Sindh, KP and Baluchistan.

FALAH showed a decrease in fertility ( 0.5 children) and improvements in family planning behavior in a relatively short time period and over a wide range of districts across Pakistan. ${ }^{8}$ The project reached more than 9 million married men and women in 20 districts with birth-spacing messages. Comparison of the results from baseline and endline surveys from the intervention areas showed that the CPR rate grew by 8.5 percentage points, from 29.6 percent at baseline (2008-09) to 37.9 percent at endline (2011-12) and unmet need dropped from 14.2 percent to 10.8 percent. Total demand for family planning grew from 64 percent to 71 percent.

This brief presents findings of a case study of FALAH's male engagement component and its contributions to these results. The document describes how the male engagement component was implemented and the outcomes achieved. Assessment of the outcomes is based on baseline and endline surveys conducted by FALAH in 2008-09 and 2011-12, and qualitative research in four districts of Punjab on community perceptions of male-focused interventions carried out by the Population Council in 2013. In addition, the case study includes relevant findings from external evaluations conducted by Contech International and Gallup Pakistan in 2011.

\section{FALAH's Objectives in Communicating with Men}

A distinguishing feature of FALAH was the recognition and active involvement of men from the beginning in creating a supportive and conducive environment for family planning. In its behavior change communication (BCC) program, the project emphasized the role of men as family leaders dedicated to ensuring the health of their wives and children. The main objectives of FALAH's communication interventions for men were:

- Increase men's understanding of the benefits of birth spacing and the World Health Organization (WHO) recommended spacing interval of 24 months for the health of mothers and newborns and overall family well-being;

- Encourage male responsibility in family planning;

- Increase interspousal communication on birth spacing, including communication initiated by men and men's responsiveness to communication initiated by women;

- Increase knowledge of correct and effective use of contraceptives, including male methods;

- Minimize fear of side effects from contraceptive use; and

- Create awareness of various sources of contraceptive information, products, and services. 


\section{A New, Socially Acceptable Message: "Birth Spacing Saves Lives!"}

FALAH repositioned family planning as a health intervention by recasting the family planning message in a "Birth spacing saves lives" paradigm. The defining trait of its communication, advocacy, and mobilization strategy was a focus on the practice of healthy timing and spacing of pregnancies (HTSP), in particular: (1) a WHO-recommended interval of 24 months from birth to the planning of the next conception; and (2) raising awareness of the risks of pregnancy related to women younger than age 18 and over age 35.

Within this overarching context, messages for specific audiences were developed to address misgivings associated with family planning and provide holistic information on contraceptive choices, details of where services could be obtained, contraceptive side effects, the Islamic viewpoint on family planning, and the direct impact of birth spacing on maternal, child, and family health.

\section{Five Communication Interventions for Men}

To communicate with men, FALAH from the onset employed five types of interventions at the interpersonal, community, and mass communication level:

1. Individual counseling through community-based volunteers, referred to as falabi workers;

2. Men's group meetings at the community level;

3. Friday sermons at mosques by sensitized local religious leaders;

4. Interactive community theatrical performances;

5. Electronic media (radio spots and television broadcasts of messages, documentaries, and discussions on family planning).

The following sections discuss in further detail each of the five interventions and their outcomes based on qualitative and quantitative data. We analyzed each intervention separately to examine the strength of that particular intervention.

To examine the effect of three of the interventions (men's group meetings, religious sermons, and electronic media), we pooled the data from men interviewed in the FALAH baseline (2,565 men) and endline (2,272 men) surveys and ran a multivariate model controlling for background factors like standard of living, education, number of children, province, region, and participation in at least one of these three interventions. After fitting the logistic regression model, we computed the predicted probabilities of six outcomes among the men exposed at least once to any of the three interventions. The six outcomes, representing the spectrum of changes in mens' attitudes and behavior toward family planning, were: (1) initiating conversation with wives on family planning in the last year, (2) approachability to wives if they wished to discuss family planning, (3) likelihood of responding positively if wives broached the subject of family planning, (4) approval of family planning, (5) shift in fertility preferences in favor of having no more children, and (6) any type of contraceptive method used by the man and his wife. The probabilities were computed after controlling for the overall period change between the baseline and endline, the background variables, and participation in the other two interventions. The probabilities thus calculated are presented for the three interventions (men's group meetings, religious sermons, and electronic media, including radio and TV).

Data on exposure to the falabi workers and interactive theater were not included as they were implemented in fewer districts (six districts and five districts, respectively). In presenting the outcomes to those interventions we use other sources of data that are noted in each respective section. 
While there was some variation in the approach, and the combination of interventions used in individual districts differed, the focus on the core message of HTSP was sustained consistently in all information, education, and communication (IEC) materials, direct interactions at the personal and community level, and media campaigns. Figure 3 presents an overview of the project's envisaged pathway of change in male fertility intentions and family planning behavior.

\section{FIGURE 3}

\section{FALAH's Envisaged Pathway of Change in Male Fertility Intentions and Family Planning Behavior}

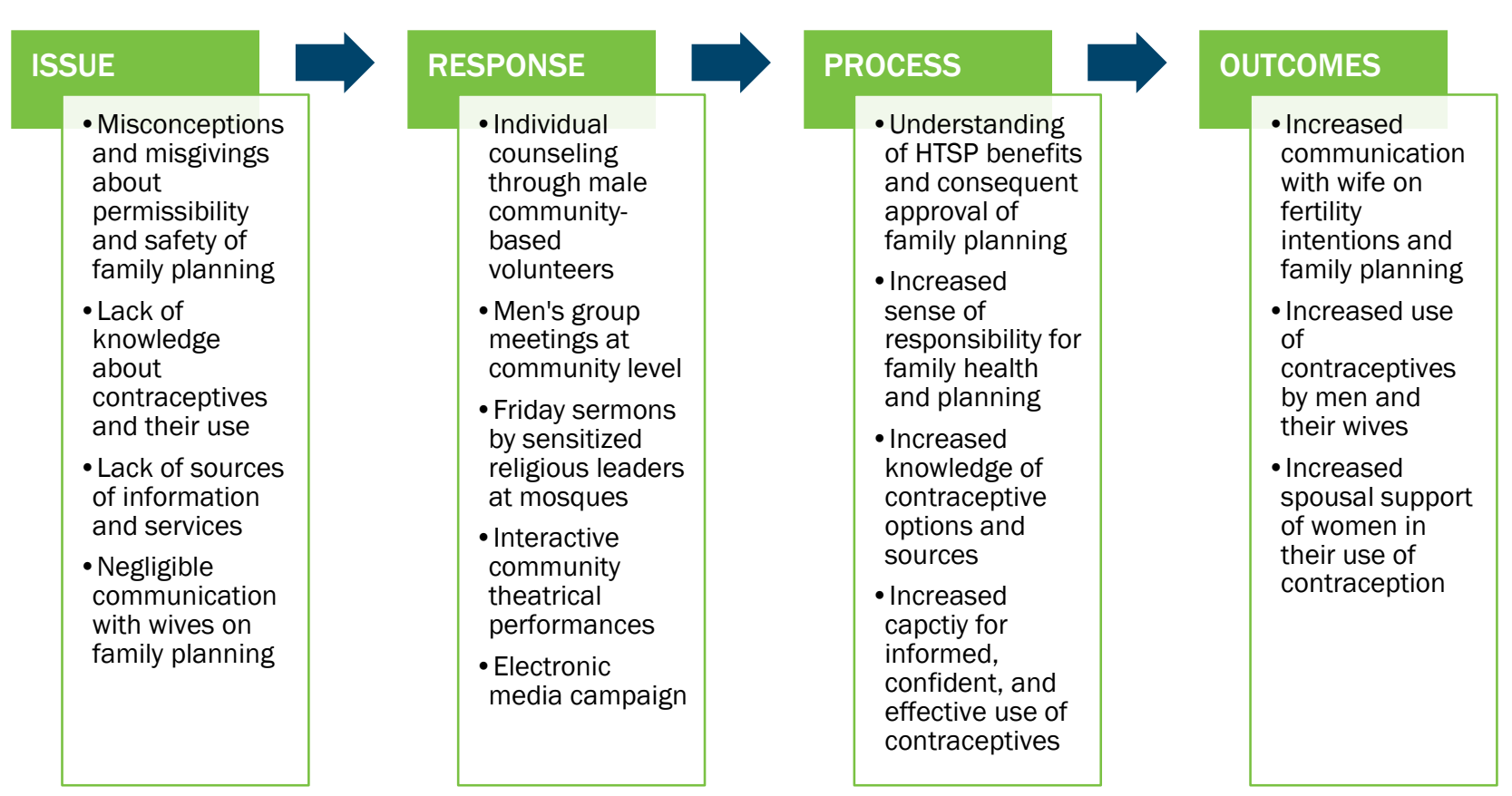




\section{Outcomes of the Male Engagement Interventions}

\section{MAN TALK: MALE COMMUNITY-BASED VOLUNTEERS}

\section{The Intervention}

In six of FALAH's target districts, a community-based approach was adopted to provide birth-spacing services to men and women in remote communities not served by Lady Health Workers (LHWs) ${ }^{*}$ or any other public health providers. The approach involved an intervention by community-based volunteers (CBVs) and was designed to sensitize husbands and wives in underserved and marginalized communities to their birth spacing needs, empower them to overcome social barriers that restrict use of family planning, and remove constraints in access to contraceptive services. The innovative aspect of this intervention was its equal inclusion of male volunteers to inform, educate, and counsel men in the communities in target districts. This was found to be a strong complement to the more conventional intervention of female workers counseling women.

Male and female CBVs, called "falahi workers," were identified from the target communities in four project districts in Sindh, one district in KP, and one district in Punjab to work with men and women, respectively. Each falabi worker was trained by the FALAH project, equipped with specially developed IEC materials, and given a nominal honorarium of US $\$ 15$ per month to undertake mobilization activities in a catchment area of about 1000 people. These mobilization activities consisted of individual and group sensitization, education, and counseling sessions separately for men and women aimed at:

- Informing and educating married men and women on the advantages of HTSP and contraceptive choices available;

- Reducing fears about the side effects of contraceptives;

- Encouraging spousal communication about birth spacing;

- Allaying misconceptions about different methods; and

- Facilitating men and women in accessing family planning services.

\section{IEC MATERIALS USED FOR FALAH INTERVENTIONS}
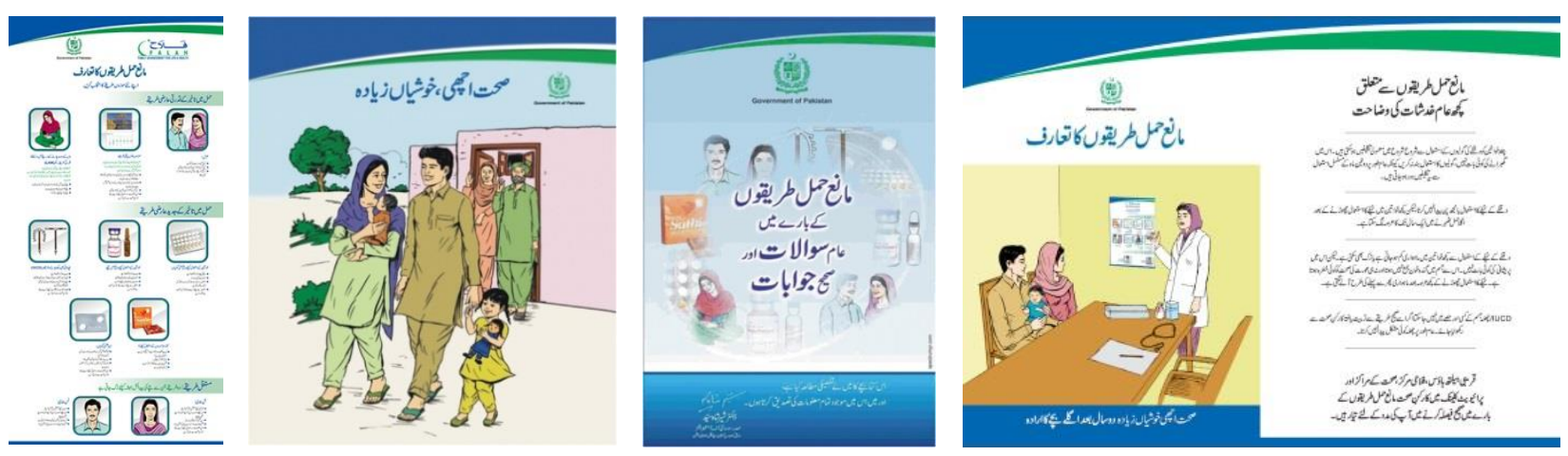

\footnotetext{
* LHWs are government employees of the Lady Health Worker Program for Family Planning and Primary Health Care. They are mandated to visit homes and provide family planning and primary health care services. However, they only cover 60 percent of Pakistan's population, leaving a large portion of residents who are not reached by such communitybased service providers.
} 
Men and women who expressed a desire to practice contraception were linked to services provided through periodic visits to the communities by Lady Health Visitors ${ }^{\dagger}$ who were especially engaged for this purpose, or alternatively, informed about the nearest service-delivery points, such as basic health units or government hospitals.

Interestingly, in the Punjab districts where male falabi workers were not recruited, participants in the qualitative study noted the need for male community-based volunteers in their areas: ${ }^{5}$

"The same way as $L H W$ s, there should be a male worker for men who can guide them about what is better for them and how to use different [contraceptive] methods. Either that, or they can go door-to-door."

-Male, in-depth interview, rural Okara

"Similar to an LHW who guides and discusses family planning with women, a man should be there to discuss, guide, and convince men about the importance of family planning."

-Male, focus group discussion, rural Bahawalpur

\section{Outcomes}

At the end of the seven-month project period, this intervention was evaluated by a third party through a survey of approximately 2,000 randomly selected married women of reproductive age as well as interviews with $270 \mathrm{CBVs}$ and 50 health-care providers in the target districts. The study found a CPR of 50 percent among the women, much higher than the national estimate of 29 percent at that time, in addition to several other positive results associated with the intervention, including much higher use of modern than traditional methods. Women also reported that their own awareness of family planning methods was greater after the intervention than before. Ninety percent of the women recalled that CBVs provided them with information on sources of family planning methods and 71 percent of current users said that CBVs were instrumental in motivating them to practice family planning. About half of the women reported that their husbands participated in intervention activities conducted by male falabi workers. ${ }^{9}$

The district health managers and care providers interviewed specifically emphasized "greater involvement of male CBVs" among measures to improve the impact of such interventions. As one respondent noted,

"Involvement of male CBVs should be throughout the project as they are the real source of inspiration for male members of the community. They can motivate heads of the family and can work even on roadsides or in the shops to achieve the plan."

-Male, district coordinator, Sukkur ${ }^{9}$

FALAH's partner, Rural Support Programme Network, has continued this activity in various programs in the districts where they work.

† Lady Health Visitors are mid-level, providers who have received two years of formal training from public health schools in Pakistan to provide reproductive health and maternal and child health services in primary health care centers. 


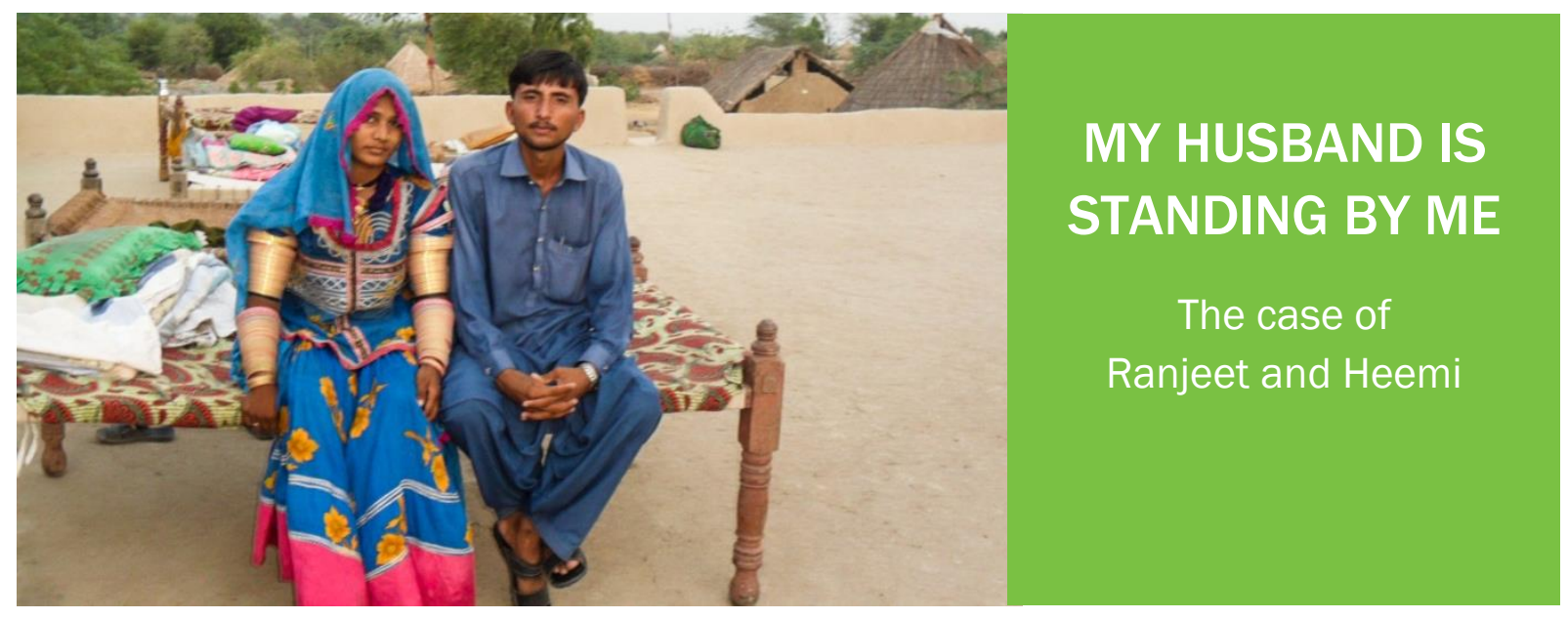

Ranjeet and his wife Heemi were both 16 when they got married in 2009. They live in a remote village of Sindh where most residents are Hindu and early marriage is part of an age-old tradition that parents were obliged to enforce. Like many other such villages, the community is not served by an LHW and people have very limited access to reproductive health information.

Before they were visited by the falahi workers, Ranjeet and Heemi had witnessed many young couples facing very serious health problems in pregnancy. A girl from their village had recently died from such complications, adding to their fears and confusion.

"We were unable to understand the reasons of her death," says Ranjeet, "But when we attended a sensitization session organized by the FALAH project, we came to realize that pregnancy before the age of 18 is dangerous for women."

What he had seen happening to other young couples, and the information and counseling provided to him by male falahi workers led Ranjeet to take a step that was novel for a young man in his community: "I did not want Heemi to face any problems in pregnancy," he says, "So we decided together to delay her first pregnancy until she turned 18."

Heemi talks about the impact her husband's support had on her ability to practice family planning. "In our society, a woman has to face a lot of criticism from relatives and neighbors if she does not get pregnant within the first few months of marriage. I do not let such criticism affect me, as my husband is standing by me and fully understands that delaying pregnancy will be very helpful for my health." 


\section{PEERS FOR PLANNING: MEN'S GROUP MEETINGS}

\section{The Intervention}

Group meetings for men were conducted in rural areas to encourage interspousal communication on birth spacing and to facilitate both positive change in fertility preferences and greater contraceptive use.

For this intervention, male community mobilization officers (CMOs), social mobilizers of the provincial population welfare departments and village health committee (VHC) members were engaged to reach out to men in areas served by LHWs. The CMOs, social mobilzers and VHC members were trained in the client-centered approach and group meeting methodology to conduct group meetings in their catchment areas using FALAH IEC materials.

In each of their assigned communities, the recruited and trained CMOs, social mobilzers and VHC members organized men's group meetings (MGMs) every three months and approximately 20-25 local men participated in each session. The majority of the participants were husbands of women who had already attended similar women's group meetings organized by FALAH in the community.
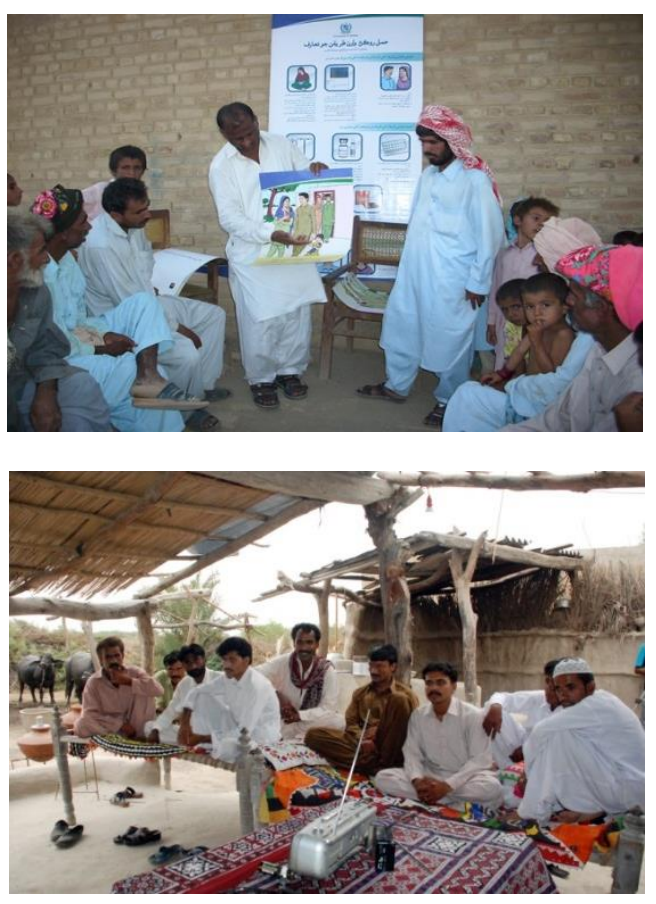

Modern and conventional contraceptive methods were discussed, including methods for both women and men, and myths and misconceptions regarding contraceptive use were clarified. This was done with the help of an audio cassette resource containing comprehensive information about various contraceptive methods, and a pictorial flip chart comparing a positive case of a couple who used contraception and a negative story about a couple who did not.

Men who were ready to adopt family planning services after the MGMs were referred to nearby public and private health facilities for contraceptive supplies.

\section{Outcomes}

The qualitative study carried out in Punjab found that women perceived FALAH's MGMs as more important than their own meetings: ${ }^{6}$

"These meetings proved to be very helpful. My husband's views were different after attending the meeting. It was very belpful for us, and we got to know which method is easy to use. Therefore, we discussed it with one another."

-Female, in-depth interview, northern Punjab

"There should be more meetings for men. A woman cannot do anything and is helpless. If there will be more meetings with men, this will be useful for their wives as well."

-Female, focus group discussion, northern Punjab

The study also revealed that men generally considered the MGMs beneficial now as well as in the future:

"I did not have much knowledge of birth spacing and its benefits. I only heard from my elders that a large family is more respectable in our culture. After participating in this MGM, I realized that I am doing wrong and I need to care for my wife and children. I discussed the matter with my wife and we mutually decided to adopt birth-spacing methods available for men. After a consultation with a bealth-care provider I got condoms for birth spacing.

-Male, in-depth interview, Dadu ${ }^{10}$ 
"It is our opinion that a man will convey the message to ten people in a meeting and the ten people will convey the message to a hundred people. In this way an 'awareness chain' will be created and it will be easier for your motivators to convey their messages."

-Male, focus group discussion, urban community in D.G. Khan

"We have a male-dominated society. The family planning program will yield excellent results and success via a men-tomen policy (men motivating men)."

-Male, focus group discussion, southern Punjab

The results of the outcome analysis are presented in Figure 4.

\section{FIGURE 4}

\section{Outcomes of Male Group Meetings}

not Exposed Exposed

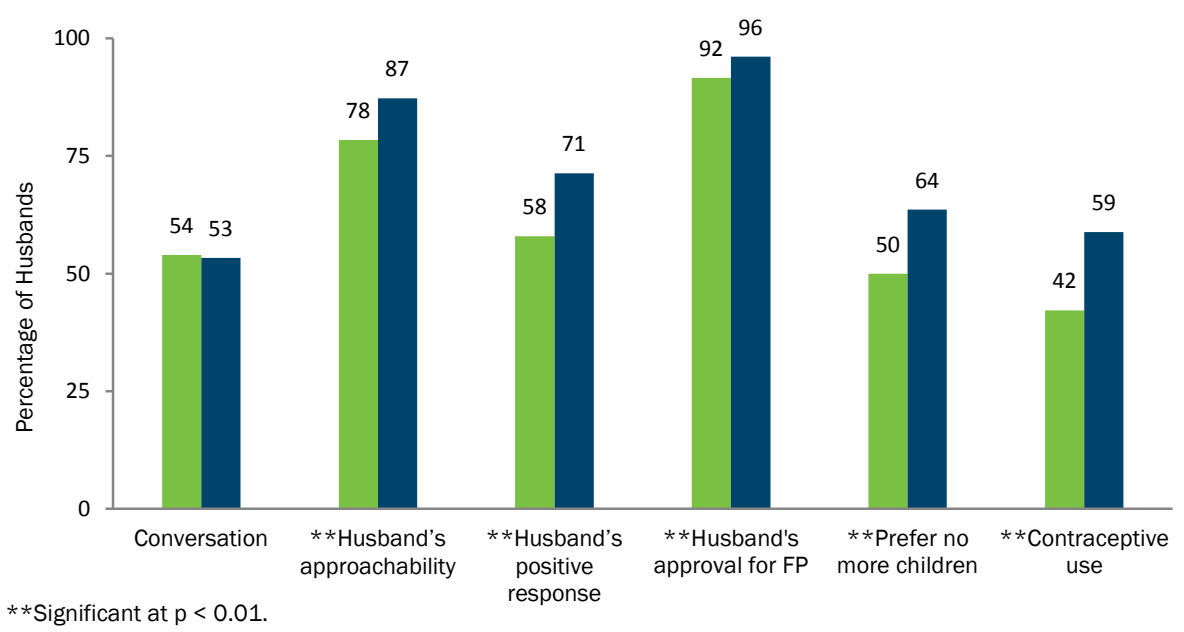

Source: FALAH Baseline Survey 2008-09 and Endline Survey 2011-12.

Interestingly, there was no difference between men exposed and those not exposed to the MGMs in whether they were likely to have a conversation on family planning with their wives. However, the likelihood of men being approachable if their wives wanted to broach the subject of family planning was higher among men who attended MGMs compared with men who were not exposed to the

intervention. Likewise, the predicted probability of men being cooperative and sympathetic if their wives brought up the subject of family planning was higher among MGM participants. While positive, these differences were also statistically significant. Such outcomes were found to cut across age and across the poorest and richest households.

The vast majority of husbands already approved of family planning, which went up just slightly. However, their preference to not have an additional pregnancy was higher among those who attended a meeting. The most significant was a difference in the likelihood of using contraception, much higher at 59 percent among those who attended MGMs. These men were likely to be those whose wives were in contact with LHWs thus positioning the couple to consider using family planning, but the MGMs may have been instrumental in making a final decision to use a contraceptive method.

Compared with a 42 percent likelihood of contraceptive use among men who did not participate in the meetings, the predicted probability of use of any contraceptive method was 59 percent among MGM participants. 


\section{CLEAR CONSCIENCE: SERMONS BY SENSITIZED MOSQUE LEADERS}

\section{The Intervention}

There is clear evidence to indicate that religious and social barriers to adopting family planning are more pronounced among men than women., ${ }^{3,1}$ FALAH identified the importance of taking onboard ulema (religious scholars) and other religious leaders to mitigate the perception that religion is opposed to family planning at the grassroots level. It was essential to engage this influential group, sensitize its members, and take its recommendations into account to introduce the "birth-spacing" paradigm of family planning successfully.

At the outset, a meeting of ulema was convened representing the major schools of Islamic thought. Participants agreed that the Quran enjoins mothers to breastfeed their children for two years, leading to natural spacing, which indicates that spacing is fully endorsed by the Quran and Sunnah (Islamic teachings). On this basis, they passed a unanimous declaration of unequivocal support for birth spacing in July 2009. The views and endorsement of the country's top ulema were captured in a 15-minute documentary entitled Farishton Nay Bhi Poocha ("Even the angels dared to ask"), which also outlined the project's strategy.

The declaration was a cornerstone in FALAH's curriculum for sensitizing religious leaders and communities to birth spacing and the Islamic perspective. The curriculum was developed by a group of scholars who visited Cairo and sought the advice of experts in this matter at Al-Azhar University, a well-known seat of Islamic teaching. In keeping with the counsel of religious scholars, it was ensured that the communication campaign would not be too direct or hard-hitting on sensitive topics. Instead, it would be conducted in a suitably subtle manner to avoid evoking a negative reaction.

A training-of-trainers approach was used to conduct 24 step-down sensitization sessions for more than 1,500 religious scholars from different sects identified by the District Population Welfare Officers to enable the scholars to become birth-spacing advocates. Participants received technical information on contraceptives and on how to clarify myths and misconceptions about contraceptive use. They learned about the health significance of birth spacing, the Islamic viewpoint on this subject, and the importance of treating women with dignity and respect and to not discriminate between boys and girls.

Religious leaders admitted that, prior to the sensitization sessions, they had harbored many misconceptions about the purpose of family planning promotion. However, once they attended the training, they understood how HTSP was a way to fulfill their responsibilities in providing guidance on family planning behavior.

"The training program has helped me understand that the spacing of births is an extremely helpful health intervention as it ensures better health of a mother and her children. I have also learned about various methods that a couple can use to this end, and the role husbands can play in the adoption of birth spacing. Now, I firmly believe that birth spacing is permitted in Islam and that it is an important cornerstone in improving family health."

-Imam, village mosque, Sindh

\section{Outcomes}

Once sensitized to family planning, religious leaders then propagated the birth-spacing message in Friday sermons, nikkah (marriage) ceremonies, and other religious gatherings attended by men in large numbers.

The qualitative study from Punjab showed a positive response from men regarding the involvement of religious leaders in family planning interventions: ${ }^{5}$ 
'The cleric's words carry more weight than the prime minister's. The cleric should deliver a speech at least three times a month on this topic according to the Quran and Hadith [Islamic teachings] so that people can be educated and motivated."

-Male, focus group discussion, rural Jhelum

"The religious leader is more influential in persuading any person; one will always prefer the words of a maulvi sabib to those of any other person (health worker, friend, or neighbor). So a religious leader is important in convincing any person, if necessary."

-Male, in-depth interview, rural Jhelum

Except for the husband's approachability, all other behavioral indicators moved in a positive direction, as the analysis of data collected in the baseline and endline surveys of FALAH indicates (Figure 5).

Of note was the dramatic improvement in one aspect of reproductive decision-making: the proportion of men reporting that they would cooperate with their wives if their wives broached the topic of family planning, with the predicted probability of a positive response being 23 percentage points higher among men who attended talks by sensitized religious leaders.

\section{FIGURE 5}

\section{Outcomes of Religious Gatherings}

Not Exposed Exposed

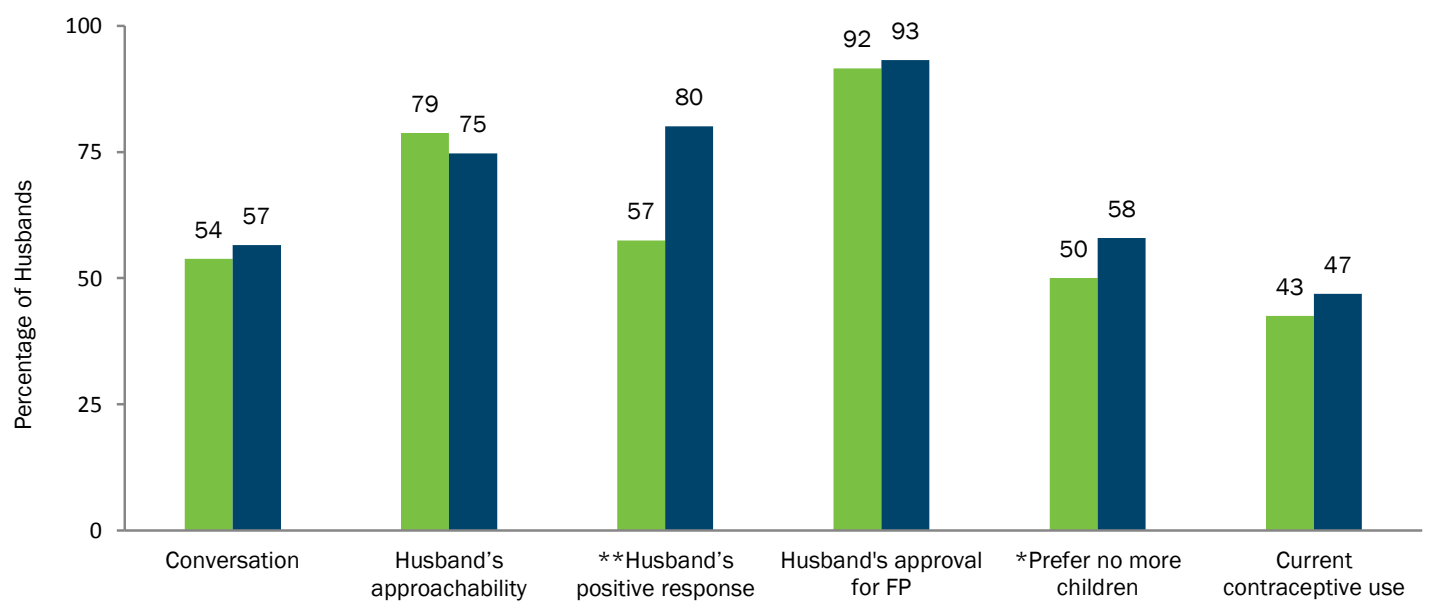

$*$ Significant at $\mathrm{p}<0.05 ; * * \mathrm{p}<0.01$

Source: FALAH Baseline Survey 2008-09 and Endline Survey 2011-12. 


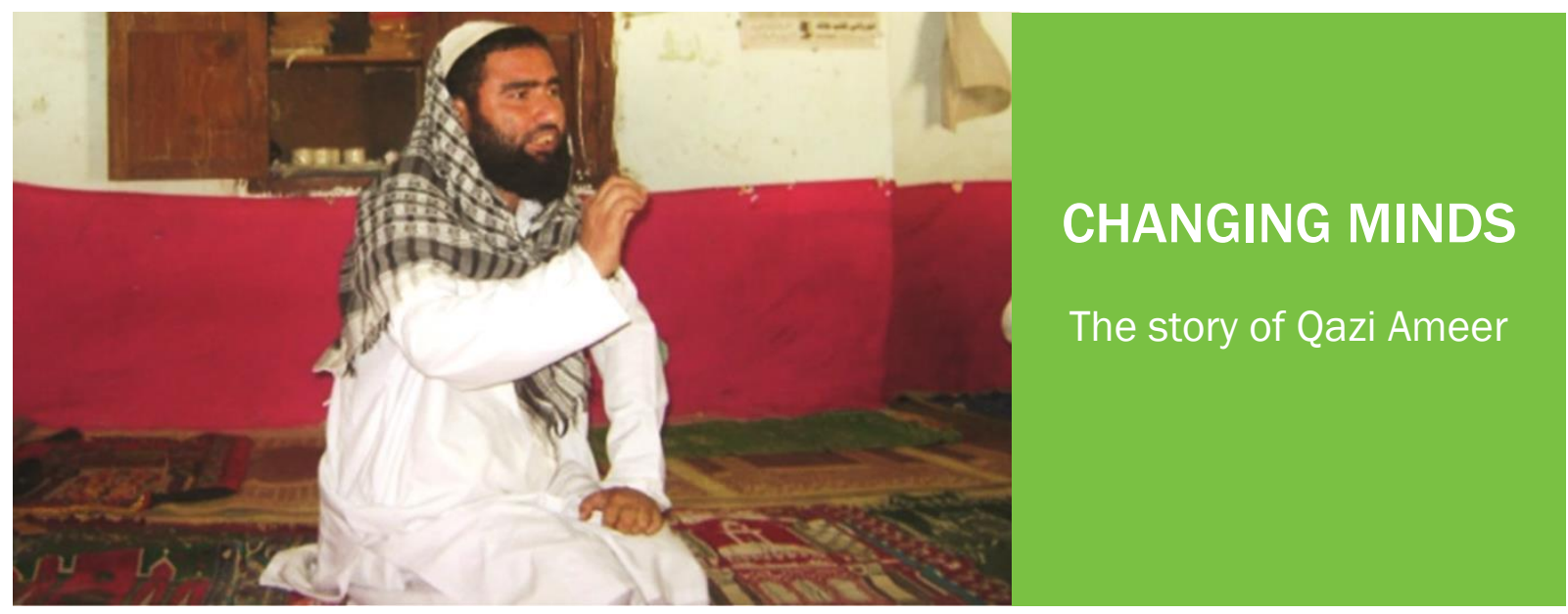

This intervention clearly facilitated the transformation of religious leaders into active proponents of birth spacing as an important health intervention for improving maternal and child health. One such leader was Qazi Ameer Ahmed Shah.

Qazi Ameer is a scholar who runs a madrasa in the village of Palai Mardundh in Khyber Pakhtunkhwa. His wife is an LHW and he used to argue with her that her work went against their religion. He was invited by FALAH to attend a three-day sensitization workshop for religious leaders, which helped clear his misconceptions and led to a complete change of stance on family planning:

"The FALAH training has really changed the way I think about family planning," he now says. "I am conveying the birth-spacing message in my Friday sermons and am now supportive of my wife providing birth-spacing services to women who need them." 


\section{COLLECTIVE REFLECTION: INTERACTIVE COMIMUNITY THEATER}

\section{The Intervention}

In selected underserved rural areas in five districts of Sindh, FALAH employed interactive theater as a platform for two-way communication with communities. Theatrical performances were organized by FALAH partner HANDS, in which local artists performed plays about family planning and associated social issues that were attended by both men and women in the communities.

The aim of this innovative "entertain-educate" approach was to desensitize communities, especially men, to the phrase "family planning" and to introduce birth spacing as a health and social

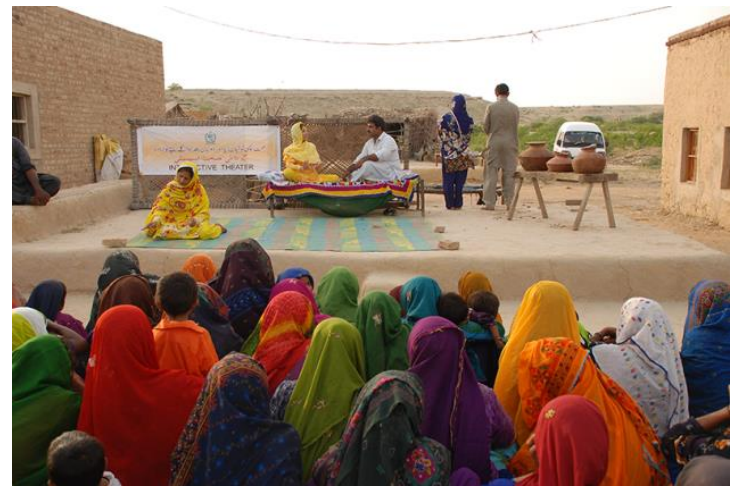
issue that needed to be discussed at the family level and, collectively, at the community level. The intervention was targeted at communities where it was previously unacceptable to openly discuss these issues. The intervention also sought to enhance communities' access to health facilities by creating linkages between them and public- and private-sector service providers.

Twelve theater groups were formed and trained by FALAH to perform in five districts. While the theater groups were open to all segments of society, efforts were made by members to enlist married women of reproductive age and their husbands. The scripts were based on a story describing the advantages of birth spacing. The audience was encouraged to participate in the performance by identifying indigenous solutions to the community problems highlighted.

More than 1,000 interactive theater performances were organized, and over 61,000 female participants and 40,000 male participants attended. Community members were offered basic health care, maternal and child health care, and family planning services through Mobile Service Units of the Sindh Population Welfare Department, which had been especially arranged in the vicinity after the performances.

"My wife was very scared about either of us adopting a contraceptive method. However, after watching an interactive theater performance on birth spacing together, our anxiety and questions were cleared and we decided that I should have a vasectomy."

-Male member of the audience at an interactive theater performance

\section{Outcomes}

The activity proved successful in generating awareness of the desirability of family planning and encouraging contraceptive use especially among men. More than 11,600 women obtained family planning methods from the Mobile Service Units and a further 617 clients were referred for other family planning services. ${ }^{8}$ 


\section{MASS COMMUNICATION: THE ELECTRONIC MEDIA CAMPAIGN}

Several studies in developing countries have found that exposure to family planning messages on mass media influences the contraceptive behavior of individuals. ${ }^{12,13}$ According to the PDHS 2012-13, 87 percent of men in Pakistan believe mass media messages are effective in persuading couples to adopt family planning. The survey also found that print media is accessible to 27 percent of urban men but to only 12 percent of rural men owing to low literacy levels.

\section{The Intervention}

Given the generally low literacy levels in the country, especially in rural areas, the FALAH mass media campaign was focused mainly on electronic media. The campaign disseminated the project's core message of birth spacing for better maternal, child, and family health to a wide audience, including and beyond the project districts, with an emphasis on highlighting men's responsibility. The primary target audience included couples of reproductive age, while the secondary target audience included influencers, policymakers, and religious leaders.

Mass media instruments included four radio spots on FALAH's birth-spacing messages; a television jingle with FALAH's key

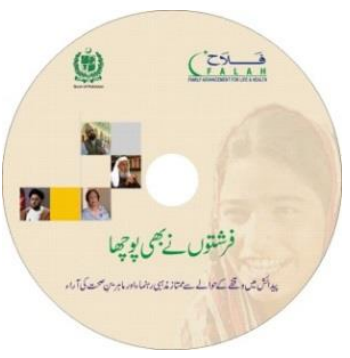
message on birth spacing; a television commercial, "Pauda" (Plant), on the dangers of early pregnancy (i.e., before the mother is 18); a television commercial, "Waris" (Heir), on the problem of preference for male children; 13 episodes of a television talk show, "Kiyoun Ke Maa Bachay Ki Sehat he Sab se Barb Kar?” (Because mother and child health is most important); and a 15-minute video documentary, "Farishtoan Nay Bhi Poocha" (Even the angels dared to ask).

Farishtoan Nay Bhi Poocha included prominent religious scholars' endorsement of birth spacing as a practice compatible with Islamic teachings as well as the views of well-known health-care providers. The documentary was aired on national and regional television channels. Endorsement by the highest authorities on religious matters in the country was intended to address the suspicions and stigma conventionally associated with family planning.

The television and radio advertisements were produced to address demand-side barriers to family planning, such as male-child preference and early marriage and child birth, along with creating awareness of the importance of HTSP and birth spacing. The ads included endorsements from prominent medical professionals. Radio advertisements were widely aired through the FM radio channels in FALAH districts and at community events organized by the implementing partners. Television advertisements were aired on

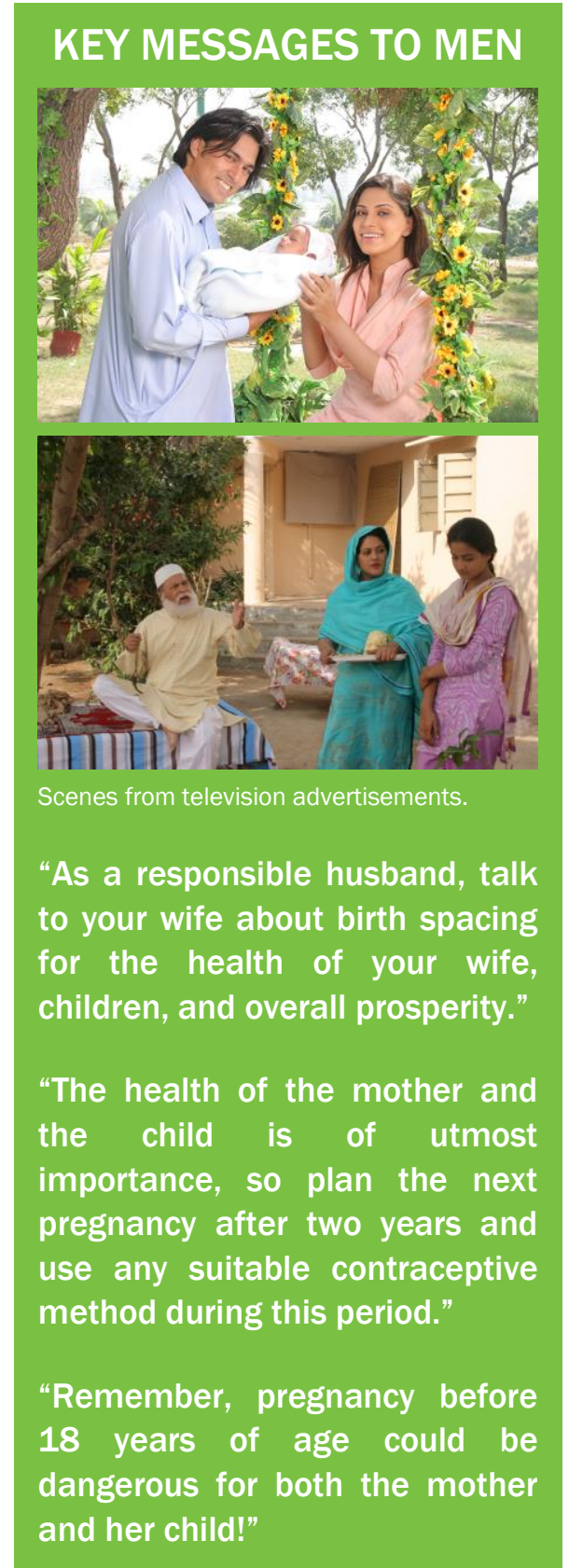


various national and regional satellite channels.

Gallup Pakistan found that 50 million people were exposed to FALAH messages, at least half of whom were men. ${ }^{14}$ Mass media exposure among men in the FALAH districts was quite extensive, with 30.7 percent having watched FALAH messages on television and 7.5 percent having heard them on the radio.

The television campaign resulted in a far stronger improvement in the predicted probability of men using contraceptives, compared with the radio campaign.

The qualitative findings of the Gallup evaluation also showed that watching family planning/birth-spacing commercials on television had a positive impact on men's perceptions about birth spacing and demonstrated the importance of reaching men. ${ }^{14}$

"It tells about the bealth of mother and child, both. It is informing about family planning by saying that an appropriate break. of two years must be taken between having children, for the good health of mother and child."

-Male, focus group discussion

"It is men who do not want to practice birth spacing even though women are willing to do so. It is very hard to convince men to practice birth spacing. These advertisements are the best way of convincing men."

-Female, focus group discussion

\section{Outcomes}

The outcomes of the intervention on men were assessed based on analysis of data collected in the baseline and endline surveys. The results are presented in Figures 6 and 7.

\section{FIGURE 6}

\section{Outcomes of Television Campaign}

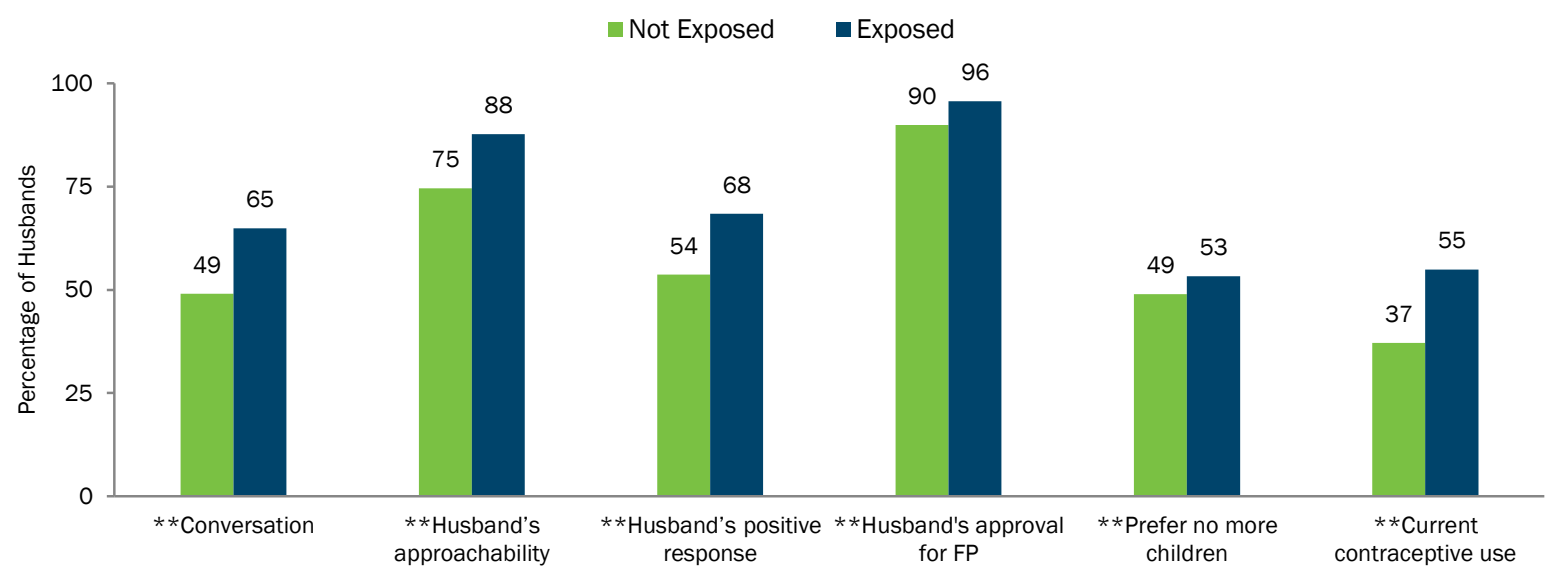

*Significant at $p<0.05 ; * * p<0.01$.

Source: FALAH Baseline Survey 2008-09 and Endline Survey 2011-12. 
FIGURE 7

\section{Outcomes of Radio Campaign}

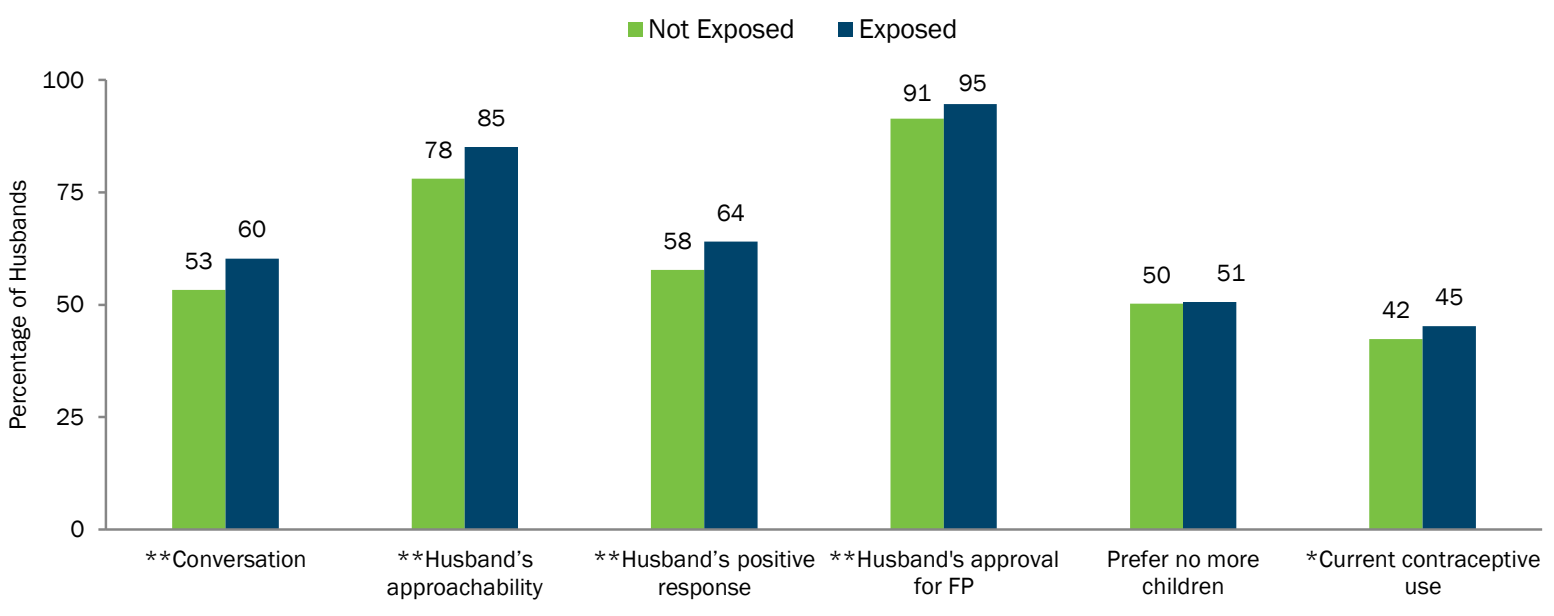

*Significant at $\mathrm{p}<0.05 ; * * \mathrm{p}<0.01$.

Source: FALAH Baseline Survey 2008-09 and Endline Survey 2011-12.

Exposure to mass media messages through both radio and television led to an increase in the predicted probability of men communicating with their wives about family planning and also of being approachable if their wives wanted to broach the subject. The likelihood of men being cooperative if their wives brought up the subject of family planning was significantly higher among men who viewed the television messages compared with those who did not. The television campaign led to stronger improvement in the predicted probability of men and their wives actually using contraceptives, compared with those who heard messages through the radio campaign. When significant in changing behaviors, the electronic media's outcomes cut across age and across the poorest and richest households. 


\section{Conclusions and Recommendations}

FALAH's experience of engaging men in its target communities bears out the finding of recent studies that Pakistani men are ready, indeed eager, to be involved directly in family planning. Implementation of the FALAH approach to male engagement in 20 districts across Pakistan's four provinces shows that male engagement can be implemented on a large scale and that it can be synchronized with interventions that target women together with men as is the case with interactive theatre or separately as with the male and female falabi workers. The findings from this case study are relevant for Pakistan and for other countries interested in promoting male engagement in family planning and in scaling up programming.

Three of the five interventions (MGMs, sermons by sensitized mosque leaders, and electronic media campaigns) were evaluated in detail for their impact on five different dimensions of family planning-related behavior. Since the processes influenced by each of the interventions vary, it is difficult to discern which of the interventions can be singled out as more or less important. Furthermore, since the interventions were not evenly spread over the districts, it is not possible to discern their full combined impact. Despite these shortcomings, there is strong evidence that exposure to television messages and the men's group meetings have been clearly influential in changing important behavioral aspects of involving men more fully in family planning programs. Data indicate that most of the male involvement indicators are moving in a positive direction, with a few showing impressive changes with these two interventions.

It is notable that the media campaigns translated into a significant increase in the proportion of men likely to have an actual conversation with their wives about family planning in the preceding year. While the men expressed strong approval for family planning and most felt they were approachable about the topic, far fewer men broke from their entrenched tradition of reserve to talk to their spouse about family planning. This indicates a need for further gender-based strategies and efforts to improve spousal communication.

There are important gaps in our evaluation of certain interventions. For example, the survey data we have for the CBV intervention were collected at the end of the project and come from women only. Nevertheless these data and the qualitative data provide important insights about the value of this approach. While contraceptive prevalence and related behaviors could not be directly measured among the over 100,000 participants of the interactive community theater intervention, the fact that more than 12 percent availed family planning services directly after the performances suggests that this is a potent intervention for underserved communities where discussion about family planning is considered taboo.

Despite limited impact on individual reproductive behavior, communicating with ulema and working with them to sensitize mosque leaders to the religious permissibility and desirability of healthy spacing and timing of pregnancies holds great potential for addressing lingering religious barriers to family planning in the most conservative parts of the country. It may be more of a promising solution to the longstanding issue of confusion, found across all segments of Pakistani society, including even the medical community, regarding the permissibility of family planning in Islam.

In shifting the focus from fertility limitation to HTSP, obtaining the documented endorsement of religious scholars representing all schools of thought, and involving these scholars in the development of its training and communication activities, FALAH presented the message of family planning in a new paradigm that could be agreed upon by all stakeholders. This communication breakthrough, coupled with a truly participatory approach that engaged rather than excluded traditional community "gatekeepers," underlies 
much of the success of the program's interventions. Thus, for example, the evaluation of the CBV intervention reported that the receptivity of remote communities in $\mathrm{KP}$ to male $\mathrm{CBV}$ s was enhanced by the fact that community members heard approving messages from their local mosques. Addressing the core issue of religious and social permissibility paves the way for communities and health workers to commit confidently to interventions, such as group counseling sessions and theater performances. The Population Welfare Departments, especially in KP, Sindh and Punjab, have built on this effort and moved forward by including religious leaders in their draft population policies.
WHERE DOES FALAH FALL ALONG THE GENDER INTEGRATION CONTINUUM?

Developed by the Interagency Gender Working Group, the Gender Integration Continuum is a framework to analyze whether and if so, how, intervention strategies address gender norms and inequities. FALAH in its conceptualization and implementation had both gender accommodating elements (i.e. works around gender differences to achieve objectives) and gender transformative elements (i.e. seeks to transform gender relations to achieve objectives). FALAH, working in a very conservative environment, acknowledged men's role as decisionmakers in women's use of family planning at the same time it aimed to transform attitudes and behaviors about spousal communication on family planning and men's approachability and responsiveness if their wives brought up the topic.

Source:bttp:/ / wnw.igwg.org/igwg media/Training/GendrContinummCate gories.pdf

The success of FALAH's interventions across a range of districts indicates that they can be applied in a variety of settings to involve men in family planning, encourage use of male methods of contraception, and encourage men to support their wives in using birth-spacing services in the interests of maternal and child health. When they are directly and effectively engaged, Pakistani men are ready to participate and share responsibility in family planning. The project's success in this respect has been noted by provincial policymakers, and the most recent provincial population policies envisage a greater focus on involving men, including replication of some of FALAH's interventions.

\section{Recognition of the Need to Engage Men in Provincial Population Policies}

The appetite for engaging men in family planning is obvious in provinces and they are moving forward by inclusion of male interventions in provincial population policies.

"Religious scholars and ulema will be associated at all levels, including at the community level, for regular communication with the male community about the benefit of birth spacing for family health and to respond to their queries, apprehensions, and misperceptions. This initiative has been tried and tested in the field and will be made a regular feature of the intervention for male involvement."

-Draft Provincial Population Policy 2014, Sindh

"The male interventions of the FALAH project were considered useful and inspirational even in non-FALAH districts and helped in reducing the hesitation of district population officers to involve men in family planning by replicating similar male-involving activities. The success of FALAH male interventions prompted us to include similar interventions in our current population policy. We have recommended a complete plan for involvement of religious leaders in all districts of Punjab."

-Deputy Secretary-Technical, PWD Punjab

"Activities to involve men in family planning by FALAH showed encouraging impact in project districts in Sindh. We have proposed replication of these interventions, especially the engaging of local religious leaders and group meetings by male workers in our population policy, which is being finalized."

-Deputy Secretary, PWD Sindh. 


\section{Implications}

FALAH's experience of engaging men has the following implications for future family planning interventions in Pakistan:

- MAKE MEN A FOCUS | The current disproportionate emphasis on women in family planning interventions needs to be replaced by a more gender-balanced approach in which men are seen as equally important partners with unique information, counseling, and service needs.

- ADOPT THE HTSP PARADIGM | "Birth spacing saves lives" is a powerful message that instantly evokes the maternal and child health implications of birth control, inspires men's protective instincts, and ultimately provides strong motivation to act on family planning intentions. This message is also harmonious with the religious argument supporting family planning. In contrast, the conventional paradigm of limiting family size is less inspiring, sometimes perceived to be at odds with Islam, and is less socially acceptable.

- OBTAIN RELIGIOUS ENDORSEMENT | Far from being against family planning, Islam supports it. This fact, and its importance in converting traditional resistance into support, has long been recognized by many other Muslim countries that took their religious scholars onboard and publicized their endorsements at much earlier stages of their family planning programs. It is high time that Pakistan followed suit. FALAH has already charted a clear path for a constructive engagement with scholars and religious leaders of all sects.

- inT'RODUCE MALE HEALTH WORKERS AND PROVIDE PEER SUPPORT TO MEN | In the same manner that LHWs serve the information and basic reproductive health needs of women, male community-based workers should be introduced to regularly visit men, provide them with information and counsel on family planning, provide contraceptives, and organize men's meetings to collectively discuss issues and conduct group counseling.

- COMMUNICATE CREATIVELY AT ALL LEVELS FALAH used a combination of mutually reinforcing interpersonal, community, and mass communication interventions to meet the full range of persuasion, information, and counseling needs of men. The relative advantages of each approach should be harnessed: mass media campaigns can play a stronger role in building a sense of shared public approval of family planning, and community interventions can provide opportunities to devise indigenous solutions to local issues, while interpersonal communications are the best source for responding to individual information and counseling needs. 


\section{References}

${ }^{1}$ National Institute of Population Studies (NIPS) [Pakistan] and ICF International. 2013. Pakistan Demographic and Health Survey 2012-13. Islamabad, Pakistan, and Calverton, MD: National Institute of Population Studies (NIPS) [Pakistan] and ICF International.

${ }^{2}$ Bongaarts J., J. Cleland, J.W. Townsend, J.T. Bertrand, and M. Das Gupta. 2012. Family Planning Programs for the 21st Century: Rationale and Design. New York: Population Council.

3 Agha, S. 2010. "Intentions to use contraceptives in Pakistan: Implications for behavior change campaigns." BMC Public Health. 10:450. doi: 10.1186/1471-2458-10-450.

${ }^{4}$ Mahmood, N. and K. Ringheim. 1996. "Factors affecting contraceptive use in Pakistan." The Pakistan Development Review 35(1):1-22.

${ }_{5}^{5}$ Tuloro, T., W. Deressa, A. Ali, and G. Davey. 2009. "The role of men in contraceptive use and fertility preference in Hossana Town, southern Ethiopia." Ethiopian Journal of Health Development. 20(3):1043-1069.

${ }^{6}$ Kamran, I., M. Khan, and Z. Tasneem. 2013. "Involving men in reproductive and fertility issues: Insights from Punjab.” Islamabad: Population Council.

7 Lasee, A. and S. Becker. 1997. "Husband-wife communication about family planning and contraceptive use in Kenya." International Family Planning Perspectives. 23(1):15-20, 33.

${ }^{8}$ Family Advancement for Life and Health (FALAH): End of Project Report. 2012. Islamabad: Population Council.

${ }^{9}$ Contech International. 2011. "Impact Evaluation of Community-Based Volunteers: A Third-Party Evaluation Study.” Lahore: Contech International.

10 "FALAH, family planning revitalized—Success stories: Improving access to birth spacing services." Islamabad: Population Council. http://www.popcouncil.org/uploads/pdfs/ar12/PopCouncil\%20Publications\%202012.pdf

11 Ali, S.R. 1999. "Men and reproductive health in Punjab: Perspectives from 37 discussion groups. Research Report No. 10.” Islamabad: Population Council.

${ }^{12}$ Westoff, C.F. and A. Bankole. 1997. "Mass media and reproductive behavior in Africa. DHS Analytical Reports No. 2." Calverton, MD: Macro International.

${ }_{13}$ Piotrow, P.T., D.L. Kincaid, J.G.I. Rimon, and W. Rinehart. 1997. Health Communication: Lessons from Family Planning and Reproductive Health. Westport, CT: Praeger Publishers.

${ }^{14}$ Gallup Pakistan. 2011. Impact of FALAH Media Campaign: A Qualitative Study. Volume III of Viewership of FALAH Media Campaign, aired July-August, 2011. Lahore, Pakistan. 



\section{The Evidence Project}

Population Council

4301 Connecticut Avenue, NW, Suite 280

Washington, DC 20008 USA

tel +12022379400

evidenceproject.popcouncil.org 